\title{
The need for an institute of hospital management
}

\author{
Lucian Jayasuriya' \\ It is essential to ensure efficient and effective utilisation of scarce resources in the government \\ health sector.
}

\section{Summary}

The monitoring mechanism of activities of the government preventive health sector is better than that of the curative sector, although much more money is spent on the latter. Recent initiatives for monitoring the curative sector should be strengthened by establishment of an institute of hospital management. The need for such an institute has been recognised for about 15 years. This need has been further emphasised by recent studies and discussions.

\section{Introduction}

The government health service functions under two broad sectors, preventive and curative. Medical Officers of Health have to send regular reports to the Epidemiological Unit and the Family Health Bureau (FHB). These ensure some monitoring of the activities of the preventive health sector. The larger proportion of money is spent on the curative sector. However, an effective mechanism of monitoring of performance of the curative sector is still in its infancy. During the last 10 to 15 years, there have been some ad hoc activities on quality assurance conducted by the Ministry of Health. The monitoring has been in a few basic areas. This activity has had very little effect on improving the performance of the curative sector.

\section{The present situation}

From March 2000, the Director Tertiary Care Services of the Department of Health has monitored 10 readily available performance indicators in the line Ministry institutions which are mostly tertiary care facilities (1). The following areas have been covered: management committees, in-service training, drug review committees, infection control committees, capital expenditure, bed occupancy, audit of maternal deaths and stillbirths, operations performed, laboratory and radiological investigations, and fuel efficiency of vehicles.

A quarterly bulletin is published and distributed to the institutions as a feedback

\section{The proposal}

A good start has been made. However, the above activities have to be expanded to cover all curative sector institutions. This is important because the problems appear to be greater in the smaller hospitals. The range of activities monitored also have to be expanded. Some additional areas of work that have to be undertaken include the following.

\section{(a) Monitoring the utilisation of medical officers}

In 1999 the government agreed to the recommendations of the Committee on employment opportunities for medical officers (2). It agreed to the recommendation to employ all medical officers who qualify from the local medical faculties and from abroad up to the year 2010. The Committee also made another recommendation, viz. "The committee recommends the establishment of a monitoring unit in the Department of Health Services which will ensure that medical officers are utilised optimally. The policy of absorption of medical graduates could be reviewed depending on the findings of the above unit". Such a unit has not been established still. It is essential that the government ensures that the staff it employs, especially medical officers, are optimally utilised. To take just one glaring example, about 1000 medical officers undergo training in the PostGraduate Institute of Medicine at any given time. There is no effective mechanism to monitor their movements and utilisation.

\section{(b) Training of managers in the hospital sector}

Except the Teaching Hospitals and General Hospitals, which are managed by full-time medical administrators, the other hospitals are managed by medical officers who are not trained in management. Some of them are not even interested in the management of their institutions. Among the other categories of staff involved in management of the hospital sector, only nursing sisters amd matrons are trained in management.

In a recent study, the Institute of Policy Studies made two important observations (3). 'First, facilities appear to be relatively under-managed, and the skills necessary for managing complex facilities such as hospitals are not yet in place in most facilities. Second, there is very little performance monitoring of hospitals by the Ministry of Health. Furthermore, the initiatives that are being taken focus primarily on tertiary hospitals; and the basic and intermediate hospitals, where the problems appear to be greatest, are not included in the plans to strengthen hospital management. 
(c) Ongoing studies of costs of patient care

This study also found that "The average costs of care in 1997 continued to be below international norms, but there remained an important degree of variation among similar facilities, with ratios of high: low cost facilities ranging from 4.3 to almost $30 . "$

Therefore, there is a urgent need for the establishment of an Institute of Hospital Management (THM). The establishment of an IHM was also recommended by the Biennial Conference on Science and Technology organised by the National Science and Technology Commission (4).

The idea of establishing an IHM was mooted about 15 years ago during the time of the Ministry of Teaching Hospitals. The Ministry requested a firm of chartered accountants to produce a draft document for this purpose. They proposed that a company under the name of $\mathrm{Na}$ tional Institute of Hospital Management be incorporated under the Companies Act No 17 of 1982 (5). They proposed that it should be managed by a Board, and that the share capital be both from the government and the private sector. The main areas of work they envisaged were training in management for all relevant hospital staff in the government and private sectors, and research in hospital management.

The alternative is for the IHM to be on the lines of the FHB. Even though it would have resource constraints, and would be able to monitor only the government sector, it will be a step in the correct diection. The Director, Tertiary Care services could be its first Head, but could have a large remit to cover all curative care institutions. His name could be changed to the Director, IHM. A separate institute with dedicated staff would have to be provided.

The establishment of an IHM is necessary to ensure that the available resources of the government health sector are efficiently and effectively utilised.

\section{References}

1. Mahipala PG. Institutional performance appraisal. A new approach to quality improvement in health care. Proceedings of the eighth annual scientific sessions of the College of Medical Administrators, October 2000.

2. Report of the Committee Appointed by the Cabinet to make Recommendations on the Employment of Medical Graduates, 1999.

3. Somanathan A, Hanson K, Dorabawila T, Perera B. Operating efficiency in public sector health facilities in Sri Lanka: measurement and institutional determinants of performance. Small Applied Research Paper No 12. Bethseda MD: Partnerships for Health Reform Project, Abt Associates Inc., 1999.

4. First Biennial Conference on Science and Technology. National Science and Technology Commission, August 2000 (Report under preparation).

5. Brief Overview Report on the Establishment of a National Institute of Hospital Management. Colombo: Ernst and Whinney, Chartered Accountants, 1987.

\title{
Doctors are influenced by pharmaceutical representation (1)
}

\begin{abstract}
Whether we like it or not, visits from the representatives of pharmaceutical companies influence our prescribing practices. For many prescribers, drug company representatives are the main source of information about new drugs and an important factor in changing prescribing behaviour. Although most doctors when asked do not believe they are unduly influenced by pharmaceutical representatives, research shows that they are.
\end{abstract}

Day R. How to make the most of a visit from a pharmaceutical company representative. Australian Prescriber 2000; 23: 97-9. 